\title{
Qualitative parameters of indoor lighting, impact on quality of life
}

\author{
Nikita Kocanovs ${ }^{1}$, Raja Kocanova ${ }^{2}$, Ineta Geipele ${ }^{3}$ \\ Faculty of Engineering Economics and Management, Riga Technical University, Riga, Latvia \\ E-mail: Inikita.kocanovs@rtu.lv(correspondingauthor)
}

\begin{abstract}
The quality of indoor lighting is a sensitive issue in the dynamic environment of daily life. The lighting industry offers a wide range of products and solutions on the huge market. However, the existing European Union and Latvian lighting regulations and standards cover questions related to the visual effect of lighting on the performance of the visual task, but it is already proven, that visual effect of lighting also affects productivity and causes emotions. Standards and regulations used by construction and real estate industries prescribe lighting parameters which are becoming outdated with a development of the solid-state lighting technologies. The aim of the paper is to review the existing lighting planning theory and practice, selecting the parameters which might have most sensitive effect as prerequisites for improving the quality of life, and might be included in quality standards, handbooks and procurement procedures for the projects, over time in building standards, norms and regulations.
\end{abstract}

Keywords: lighting quality, visual and non-visual effect of lighting, quality of life.

\section{Introduction}

Lighting has already played an important role in human life since the existence of mankind. Light has a great impact on human well-being, health and productivity. Since the beginning of $19^{\text {th }}$ century, when Thomas Edison patented the first incandescent bulb, light sources have undergone evolution. Nowadays artificial lighting fixtures - lamps and luminaires are widely used not only as a light source, but also as a design element for indoor, outdoor, household appliances, vehicles, etc. In recent years, luminaires have evolved to become more economical, with wider application, longer working lives, positive effects on human health and other aspects. For these reasons, more and more individuals and legal entities are focusing on the latest solutions that meet performance and sustainability performance. The choice factors are different; they may differ from the purpose of use, the technical characteristics, the duration of use, the price of the market, the status of the manufacturer and other factors.

The lighting industry offers a wide range of products and solutions on the huge market. According to researchers, the global lighting market is growing steadily, and is expected to exceed a market size of EUR 100 billion in 2020 . General lighting is the largest lighting market, is expected to rise to around EUR 83 billion by 2020 - around 80 percent of the total market (McKinsey, 2012). Global lighting product market trend by sector presented in Figure 1.

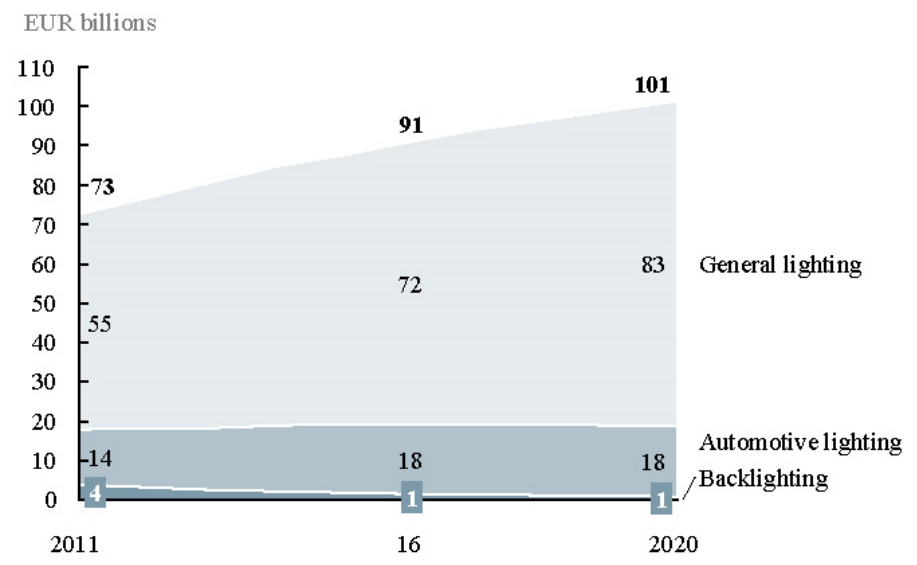

Figure 1. Global lighting product market trend (source: McKinsey’s 2012 Global Lighting Market Model)

(C) 2019 Authors. Published by VGTU Press. This is an open-access article distributed under the terms of the Creative Commons Attribution (http://creativecommons.org/licenses/by/4.0/) License, which permits unrestricted use, distribution, and reproduction in any medium, provided the original author and source are credited. 
For a long time we have known that light allows us to see, aiding orientation and enhancing safety. But light can do more than enabling vision. Light has the power to energize, relax, increase alertness, cognitive performance and mood, and to improve the day-night-rhythm of people. These biological and emotional benefits of light should not be underestimated. Recent research has shown these benefits in nearly every area of application. Despite current trends in legislation and practice, light is concerned with much more than energy efficiency. The true value lies in the combination of excellent visual, biological and emotional benefits (LightingEurope, 2014). The combination of visual and not-visual effects of lighting creates the term "Human Centric Lighting".

Industry association "LightingEurope" represents lighting industry in Europe and is the voice of more than 1000 lighting companies, has defined development challenges for the lighting industry by 2025 , focusing on the quality of life that will develop within the circular economy (Figure 2). In the coming decade, the development of new lighting systems will enable the properties of natural lighting to increase the quality of life in many daily situations. This will be the case in education, in leisure time, in healthcare, in elderly homes or in business. (LightingEurope, 2016).

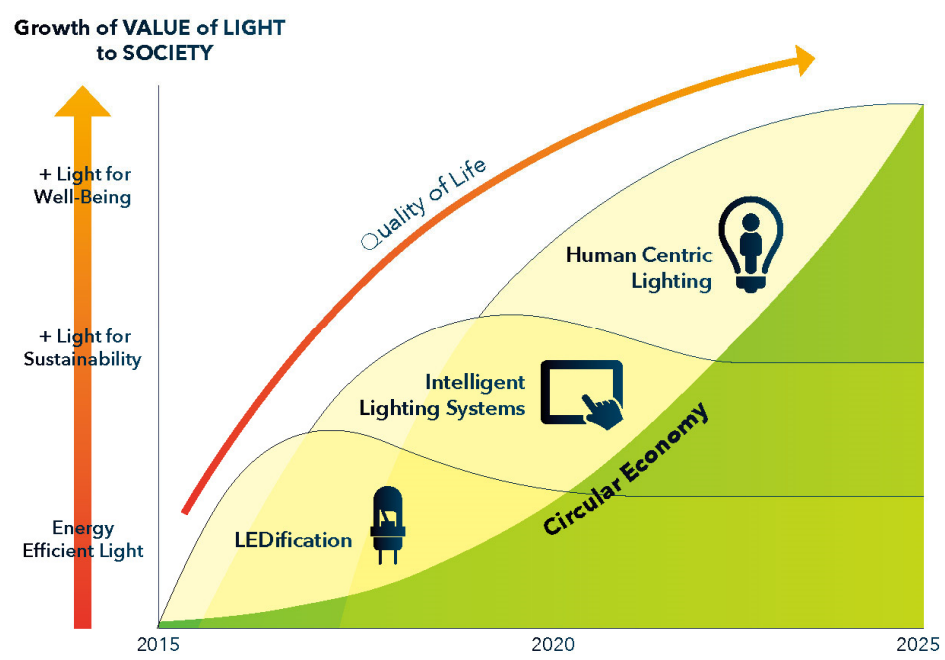

Figure 2. Strategic Roadmap European Lighting Industry (LightingEurope, 2016)

However, the existing European Union and Latvian national lighting regulations and standards cover questions related to the visual effect of lighting on the performance of the visual task. Due to financial reasons and lack of information, construction and real estate sectors do not pay the necessary attention to parameters that cause non-visual effects of lighting, although research proves their impact on human health and advanced solutions are developed.

\section{Parameters of applicable standard EN 12464-1}

The most well-known indoor lighting standard in the world is the European standard EN 12464-1 Light and lighting Lighting of work places - Part 1: Indoor work place, defines the purpose of lighting as "giving people the ability to perform visual tasks efficiently and accurately", for which the main criterion is "a maintained illuminance over the task area on the reference surface, which may be horizontal, vertical of inclined" and the work area should be lit as uniformly as possible.

European standard EN 12464-1 is a product of detailed discussion. Like the preceding edition published in March 2003, it covers all the relevant indoor applications. However, it has been revised and extended in a number of places. Published in August 2011, it documents the state of the art. EN 12464-1 applies throughout Europe (Licht, 2013).

To determinate parameters of ligting for the projects, construction and real estate industries are used to apply European Standard specifies lighting requirements for humans in indoor work places, which meet the needs for visual comfort and performance of people having normal ophthalmic (visual) capacity (EN 12464-1, 2011).

Sample of of lighting requirements for interior areas, tasks and activities required by standard are shown in the Figure 3.

\begin{tabular}{|l|l|c|c|c|c|c|}
\hline Ref. no. & Type of area, task or activity & $\bar{E}_{\mathrm{m}}$ & $U G R\llcorner$ & $U_{0}$ & $R_{\mathrm{a}}$ & Specific requirements \\
\hline
\end{tabular}

Figure 3. EN 12464-1; schedule of interior areas, tasks and activities (EN 12464-1, 2011) 
Mentioned standard includes parameters such as the amount of light on surface $(\bar{E})$, color rendering index $\left(R_{\mathrm{a}}\right)$, illumination uniformity $\left(U_{0}\right)$, and glare limitation index (UGR).

These parameters are applied only to norms and requirements for workplaces that are production sites, public places, educational institutions, offices, etc. In residential buildings, public places, urban evironment projects focus on the quality of lighting is quite superficial.

EN 12464-1 may be applicable to the creation of lighting projects, but due to different assumptions they are not necessarily comparable. The standard is not necessarily applicable by default; it is a recommendation, which can be included included in the project quality manual by the request of the customer (developer).

Parameters of lighting as $\bar{E}, R_{\mathrm{a}}, U_{0}$ and UGR describe and affect visual performace of photo receptors (rods and cones) of the human eye, but do not have sensitive impact on biological and emotional condition. Biological rhythms and cognitive functions of humans depend on the specific lighting preferences. Benefits can be achieved with the help of a new technology that allows adapting light color temperature, light distribution, spectrum, intensity and temporal characteristics of the light, so that it is more reminiscent of natural conditions. Therefore, optimization of the Human Centric Lighting solution for non-visual effect is possible only when user context is taken into account. This requires a special and individual approach, based on a deep understanding of the personal and environmental conditions.

It is obvious that parameters described in standard EN 12464-1 can not secure the conditions for the development of Human Centric Lighting solutions. Basically it means that industriy can not focus on the quality of life and dvelop according to strategic roadmap, if products will be applied according to requirements of EN 12464-1.

\section{LiDO's procedure, design based approach and metrics}

Lighting design practice offers the procedure which extends the use of illumination metrics beyond specifying lighting conditions for workplaces to encompassing the full range of indoor human activities. It starts from a consideration of lighting factors that influence the overall appearance of the space before focussing upon details.

The Lighting Design Objectives (LiDOs) Procedure is based on the proposition that the prime purpose of indoor lighting is to satisfy peoples expectations for how lighting may influence the appearance of their surroundings, where surroundings are taken to include room surfaces, furnishings, objects of interest, visual tasks and other people - in fact, all the things that people respond to visually in their surroundings. This definition of purpose places emphasis upon providing illumination for its influence on appearance rather than on performance, but this should not be seen as denigrating lighting's role in providing for visibility (Cuttle, 2018).

According to LiDO's procedure, as the technical basis, the illumination within the space is characterised by two metrics:

1. Mean room surface exitance (MRSE) is the area-weighted average exitance $\left(l \mathrm{~m} / \mathrm{m}^{2}\right)$ of the surrounding surfaces within the indoor space. It equals the average flux density of the indirect flux field within the space, and it serves as the measure of ambient illumination. (As illuminance is the density of flux incident on a surface, exitance is the density of flux exiting, or emerging from, a surface) (Cuttle, 2015).

$$
M R S E=\frac{\text { First reflected flux FRF }}{\text { Room absorption } A \alpha}=\frac{\sum E_{r s}(d) A_{r s} \rho_{r s}}{\sum A_{r s}\left(1-\rho_{r s}\right)},
$$

where: $A_{r s}$ - area of room surface rs; $E_{r s(d)}$ - direct component of illuminance on room surface rs; $\rho_{r s}-$ reflectance of room surface rs; $\left(1-\rho_{r s}\right)$ - absorptance of room surfacers (Cuttle, 2015)

MRSE is measured at the place (or points) in the volume of the space, not the surface or plane. Although it is a fairly simple calculation of metrics, its measurement is complicated by the need to exclude direct light flow. There are currently no suitable meters available, the concept of the MRSE measuring device is presented. This device can identify direct light sources and reduce their effects.

2. Target/ambient illumination ratio (TAIR) is the ratio of total illuminance on a target surface, to the ambient illumination level indicated by MRSE. (Cuttle, 2015)

$$
T A I R=\frac{\text { Target illuminance } E_{t g}}{\text { Ambient illuminance MRSE }}=\frac{E_{\operatorname{tg}(d)}+M R S E}{M R S E},
$$

where: $E_{\operatorname{tg}(d)}$ - direct component of of target illuminance; MRSE - Mean room surface exitance (Cuttle, 2015).

Tables 1 and 2 suggest plausible relationships based on a review of recent research studies and other anecdotal information (Cuttle, 2017). 
Table 1. Tentatively proposed PBI/MRSE relationship (Cuttle, 2017)

\begin{tabular}{|l|c|}
\hline $\begin{array}{c}\text { Perceived Brightness of illumination } \\
(\mathrm{PBI})\end{array}$ & $\begin{array}{c}\text { MRSE } \\
\left(\mathrm{l} \mathrm{m} / \mathrm{m}^{2}\right)\end{array}$ \\
\hline Bright & 150 \\
Slightly bright & 120 \\
Neither dim nor bright & 90 \\
Slightly dim & 60 \\
Dim & 30 \\
\hline
\end{tabular}

Table 2. Tentatively proposed visual emphasis/target-ambient illuminance ratio relationship (Cuttle, 2017)

\begin{tabular}{|l|c|}
\hline \multicolumn{1}{|c|}{$\begin{array}{c}\text { Visual emphasis } \\
\text { (VE) }\end{array}$} & TAIR \\
\hline Emphatic & 40 \\
Strong & 10 \\
Distinct & 3 \\
Noticeable & 1.5 \\
Absent & 1.0 \\
\hline
\end{tabular}

Unlike EN 12464-1, which defines the lighting conditions for work surfaces, LiDO's procedure extends the use of lighting conditions and covers the entire spectrum of human activities in a space (Table 3). It takes into consideration lighting factors that impact the overall appearance of the space before focussing on details. General factors of lighting create conditions of to how people participate in activities related to the spaces they occupy.

Table 3. A comparison of determining factors involved in the conventional calculation procedure that form the basis of lighting standard as EN 12464-1 and those factors involved in the LiDOs Procedure (Cuttle, 2018)

\begin{tabular}{|l|l|}
\hline \multicolumn{1}{|c|}{ Conventional Procedures as 12464-1 } & \multicolumn{1}{c|}{ The LiDOs Procedure } \\
\hline $\begin{array}{l}\text { The purpose of lighting is to enable visual tasks to be } \\
\text { performed efficiently and accurately. }\end{array}$ & $\begin{array}{l}\text { The purpose of lighting is to satisfy (or better to exceed) peo- } \\
\text { ples' expectations for how lighting may influence the appear- } \\
\text { ance of their surroundings. }\end{array}$ \\
\hline $\begin{array}{l}\text { Illumination adequacy for a given activity is determined } \\
\text { by the reference plane illuminance, typically measured } \\
\text { on the horizontal working plane (HWP). }\end{array}$ & $\begin{array}{l}\text { Perceived adequacy of illumination (PAI) for a given activity is } \\
\text { determined by the density of the indirect flux field, for which } \\
\text { the metric is mean room surface exitance (MRSE). }\end{array}$ \\
\hline $\begin{array}{l}\text { Efficient lighting directs flux onto the HWP, as only } \\
\text { flux incident on the HWP adds to reference plane illu- } \\
\text { minance. }\end{array}$ & $\begin{array}{l}\text { Efficient lighting directs flux onto high reflectance surfaces as } \\
\text { all reflected flux adds to the perceived brightness of illumina- } \\
\text { tion (PBI) indicated by MRSE. }\end{array}$ \\
\hline $\begin{array}{l}\text { Illumination over the reference plane is to be as uniform } \\
\text { as possible. }\end{array}$ & $\begin{array}{l}\text { The illumination distribution is chosen according to illumina- } \\
\text { tion efficiency or illumination hierarchy priorities, and is speci- } \\
\text { fied in terms of target/ambient illuminance ratio (TAIR). }\end{array}$ \\
\hline Light the task, then attend to the space. & $\begin{array}{l}\text { Light the space, then attend to the details. Visual tasks are } \\
\text { treated as detail. }\end{array}$ \\
\hline $\begin{array}{l}\text { Select the luminaire; work out the layout; then calculate } \\
\text { the required lamp flux. }\end{array}$ & $\begin{array}{l}\text { Specify the lighting design objectives (LiDOs); determine the } \\
\text { direct flux distribution (DFD); then plan the layout and select } \\
\text { the luminaires. }\end{array}$ \\
\hline
\end{tabular}

LiDO's procedure does not include chromatic properties of lighting; availability of daylight; effects of outdoor lighting; levels of emergency lighting or non-visual aspects of light exposure, but application of LiDO's procedure in practice can be considered as an extension of technical requirements for the projects by specifying minimum lighting levels in terms of minimum MRSE values. Determinating of TAIR values in the spaces can affect efficiency of lighting installation, by taking into account reflection properties of interior elements.

\section{Evaluating color rendition}

The overall color rendering index ( $R_{\mathrm{a}}$, usually called CRI) of the Commission Internationale de l'Eclairage's (CIE's) has been used permanently for 50 years. EN 12464-1 specifies values of colour rendering index $R_{\mathrm{a}}$ as a parameter for visual performance and the feeling of comfort and well being colours in the environment, of objects and of human skin, shall be rendered naturally, correctly and in a way that makes people look attractive and healthy. The maximum 
value of $R_{\mathrm{a}}$ is 100 . The minimum value of colour rendering index for distinct types of interiors (areas), tasks or activities (EN 12464-1, 2011) are given in schedule of interior areas, tasks and activities (see Figure 1).

With the development of solid-state lighting (LED technology), which provides more opportunities for spectral engineering than other conventional types of light sources, the limitations and deficiencies of $R_{\mathrm{a}}$ became increasingly noticeable. Within this context, the Illuminating Engineering Society (IES) formed the color metrics task group, operating under the IES Color Committee, which produced the technical memorandum IES TM-30-15: IES Method for Evaluating Light Source Color Rendition (IES, 2018). Color scientific researches support this new method, which provides even more accurate color rendering measurement. To evaluate the color rendering of a light source, the TM30-15 rating includes a number of measures as Fidelity Index, $R_{\mathrm{f}}$, Gamut Index, $\mathrm{Rg}$, Color Vector/Saturation Graphics, 16 hue-based fidelity indices, 16 hue-based chroma indices, 1 skin-specific fidelity index, 99 individual fidelity values. Comparison of the CIE Test-Colour Method (commonly known as CRI) and IES TM-30-15 is shown in Table 4.

Table 4. Comparison of the CIE Test-Colour Method (commonly known as CRI) and IES TM-30-15 (U.S. Department of Energy, 2015)

\begin{tabular}{|l|l|l|}
\hline & \multicolumn{1}{|c|}{ CIE 13.3-1995 (CRI) } & \multicolumn{1}{c|}{ IES TM-30-15 } \\
\hline Year of Issuance & 1965,1974 (Revision), 1995 & 2015 \\
\hline Color Space & CIE 1964 U* $* W^{*}$ & CAM02-UCS (CIECAM02) \\
\hline Number of Color Samples & 8 general (for Ra) plus 6 special (for Ris) & 99 \\
\hline Color Volume Coverage & Limited & Full and equal \\
\hline Saturated Samples & No & Yes \\
\hline Sample Types & Munsell samples only (limited pigments) & Variety of real objects \\
\hline Sample Spectral Uniformity & No & Yes \\
\hline Reference Illuminants & Blackbody radiation, CIE D series & Blackbody radiation, CIE D series \\
\hline Reference Transition & Sharp at 5000 K & Blended between 4500 K and 5500 K \\
\hline Output Measures & General index, Ra (fidelity) & $\begin{array}{l}\text { Fidelity Index, Rf } \\
\text { Gamut Index, Rg } \\
\text { Color Vector/Saturation Graphics } \\
16 \text { hue-based fidelity indices } \\
16 \text { hue-based chroma indices } \\
\text { 1 skin-specific fidelity index } \\
\text { 99 individual fidelity values }\end{array}$ \\
& 6 special indices, Ri (fidelity) & to 100, consistent scaling \\
\hline Score Ranges & &
\end{tabular}

Although technical differences between the IES TM-30-15 and the CIE CRI system may be completely invisible to many users. Of greater practical importance is the new information that the TM-30 provides in addition to the improved average for color accuracy.

Increased data availability for color rendering can benefit users, designers, specifiers, manufacturers, researchers, although the transition from the usual and simple CIE CRI (Ra) will require considerable effort. Expected requirements include the establishment of specification criteria, design guidelines and istructions for reading of the measures. IES TM-30-15 still the new method, but with a big potencial within rapid development of solid-state (LED) ligthig applications, the data exchange infrastructure should be developed through the collaboration of designers, engineers, manufacturers, specifiers, researchers, and regulators.

\section{Non-visual effects of lighting}

The impact of lighting conditions on the human body is still often underestimated. Light is essential for many physiological and psychological processes in human body. Despite its central role in the vision, it can activate biological functions, enhance concentration, and enhance our spirit.

Light is a potent stimulus for regulating circadian, hormonal, and behavioral systems. In addition, light therapy is effective for certain affective disorders, sleep problems, and circadian rhythm disruption. These biological and behavioral effects of light are influenced by a distinct photoreceptor in the eye, melanopsin-containing intrinsically photosensitive retinal ganglion cells (ipRGCs), in addition to conventional rods and cones (Lucas et al., 2014).

Melanopsin is a type of photopigment responsible for the light sensitivity of the retinal ganglion cells (ipRGC). Its highest sensitivity lies between 450 and $530 \mathrm{~nm}$ (half-width) with a maximum of $490 \mathrm{~nm}$. By stimulating this dye molecule by means of light, the ipRGC sends out nerve signals that trigger biological light effects. Even though there are different subtypes of ipRGC gibt and, according to what we know today, the other photoreceptor cells in the retina 
contribute to the biological effects, melanopsin-containing ganglion cells contribute most to the biological effects of light (Licht, 2018).

It is clinically proven by neurobiologists that at the same illuminance level, lighting colour temperature (CCT) and spectral power has a strong melanopic effect on biological system. The spectrum of activity for melantopic light effects describes the relation between the light spectrum and biological effect.

To achieve an optimal biological impact, the following illuminance levels and colour temperatures are recommended by guidelines for human centric lighting. Encouraging concentration and alertness during the day keep illuminance between 300 and $500 \mathrm{~lx}$ on the eye throughout the entire work day. The lighting level should be equal to daylight quality until the early afternoon, the colour temperature should be at least $5500 \mathrm{~K}$. The use of only warm white light combined with daylight during the day creates inappropriate lighting moods. During daytime, at least neutral white light colours should be used. At the end of the day reduce biologically effective blue components to a minimum. Use warm white light with $2700 \mathrm{~K}$ or a maximum of $3000 \mathrm{~K}$. Even for standard illuminance levels with the aim of performing visual tasks, this is a good compromise between a good quality of vision and not too strong biological impact (Licht, 2018).

EN 12464-1 does not provide any recomendatioons in terms of non visual effect of correlated colour temperature (CCT). Dstandard describes it as the choice of colour appearance is a matter of psychology, aesthetics and what is considered to be natural. The choice will depend on illuminance level, colours of the room and furniture, surrounding climate and the application. In warm climates generally a cooler light colour appearance is preferred, whereas in cold climatesa warmer light colour appearance is preferred (EN 12464-1, 2011).

Non-visual effects of light should be an additional consideration during the development of the requirements for the design and operation of human environments.

\section{Light flicker}

Flicker can be defined as a rapid repetitive change in brightness (Rea, 2000). At a minimum, flicker is a distraction. However, it can also become a hazard to health, provoking an increased incidence of headaches and even epileptic seizures (Wilkins, Veitch, \& Lehman, 2010).

Nowdays, with a huge availibility of LED light sources, the light quality of LED luminaires can vary greatly depending on the choice of key components. One of the crusual components is invisible flickering caused by the quality of the electronic balast.

There are two main types of flicker: visible and invisible. Visible flickering is generally considered unacceptable except special applications for safety, attraction of attesion or leisure etc. The invisible flicker is perceived unconsciously, but it has a biological effects on humans described above.

In EN 12464-1 is mentioned that lighting systems should be designed to avoid flicker and stroboscopic effects. (EN 12464-1, 2011). In case of visible flickering it is possible to fulfill the requirement. In case of invisible flicker which is caused by rapid fluctuations in the voltage of the power supply or incompatibility with an external dimmer, standard doesn't prescribe any measures for flicker in lighting system.

Flicker of light can be characterized by its dominant frequency and modulation depth (the variation between the maximum and minimum intensity). The flicker factor represents a number expressing the flicker amount of the light source, the maximum-to-minimum ratio of the luminous flux.

Illuminating Engineering Society of North America (IESNA) has defined two metrics for flicker: Percent flicker and Flicker index (see Figure 4).

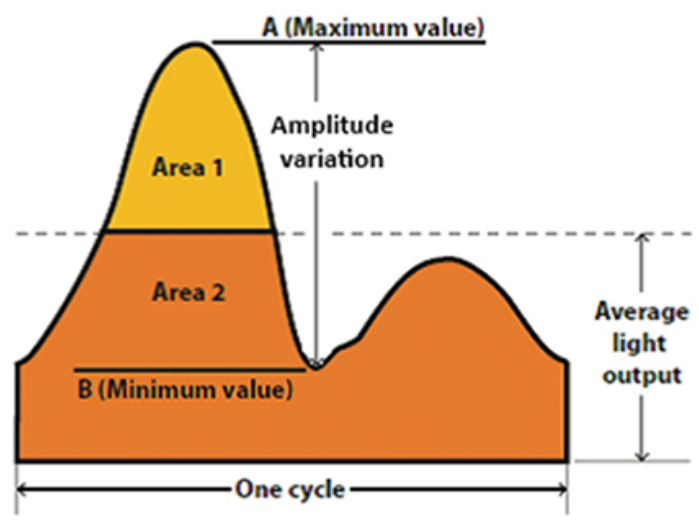

Figure 4. Periodic waveform characteristics used in the calculation of flicker metrics (IES, 2011) 
Percent flicker is a relative measure of the cyclic variation in output of a light source (i.e., percent modulation). This is also sometimes referred to as the "modulation index" (IES, 2011) From the Figure 4:

$$
F_{\%(\text { percent flicker })}=\frac{A-B}{A+B} \cdot 100 \%,
$$

where: $A$ - maxima output value of a light source; $B$ - minimal output value of a light source (IES, 2011).

Flicker index is a "reliable relative measure of the cyclic variation in output of various sources at a given power frequency. It takes into account the waveform of the light output as well as its amplitude," according to the IES handbook (IES, 2011). From the Figure 4:

$$
F_{i(\text { flicker index })}=\frac{\text { Area } 1}{\text { Area } 1+\text { Area } 2} .
$$

Percent flicker can be measured by specialized meters, so-called "flicker meters". Usually they also measure the flicker frequency of the light. Low measuremet values of percent flicker $\left(F_{\%}\right)$ or flicker index $\left(F_{i}\right)$ does not guarantee high quality lighting. Flicker frequency is important to check a given light source for not causing any flicker problems frequency and percent flicker have to be measured.

The Institute of Electrical and Electronics Engineers (IEEE) P1789 committee has been working on light flicker for several years, in 2015 has published recommendations based Flicker Modulation metrics. On Figure 5 flicker modulation depth (percent flicker) is shown as a function of flicker frequency.

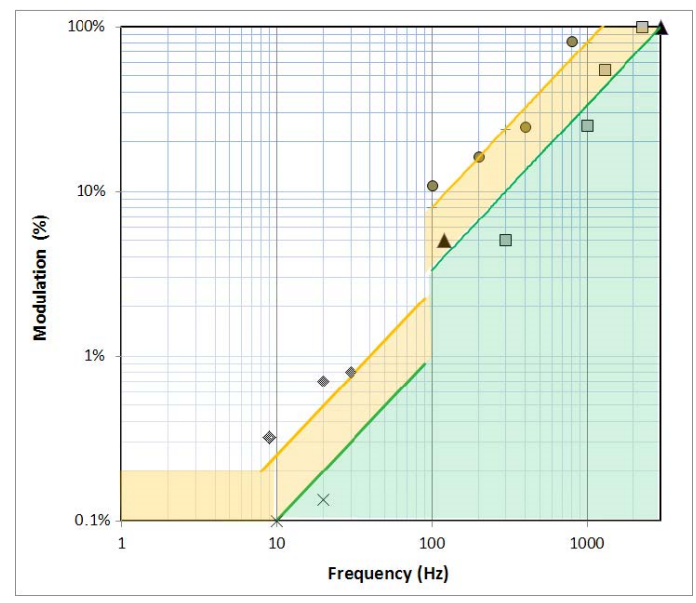

Figure 5. The low-risk (yellow) and no-observable-effect (green) regions for flicker as a function of the frequency and modulation percentage (IEEE, 2015)

Flicker is a very important issue of solid-state lighting (LED) technology. At the moment, no regulation of the flicker of light is implemented in various norms for the quality of lighting. Developers, designers, engineers, manufacturers, specifiers, must consider the risks associated with flickering, for the design and operation of built environments.

\section{Conclusions}

Light has three main functions for humans. It ensures visibility (allows seeing well), light affects our emotional state, (light and shade, color and contrast help determinate mood) and a third very important dimension: the light affects our biological functions, affects hormone levels and controls circadian rhythm.

Effect of lighting is a relatively short physiological process, motivating and regulating activity, reflecting the subjective significance of objects and situations, and represented in the form of experience.

Modern theory and practice of lighting planning presents a variety of lighting characteristics that describe more detailed quality features and non-visual lighting effects. With the advent and development of i solid-state lighting (LED) technology, it becomes possible to control a variety of lighting parmeters to obtain wholesome effects.

Applicable norms and standards as EN 12464-1 do not include mentioned characteristics that can be classified as qualitative, being satisfied with outdated quantitative parameters. In addition to the parameters prescribed by EN 12464-1, as prerequisites for improving the quality of life in real estate development and the urban environment projects, it would be expedient to develop proposals for the inclusion of qualitative parameters of lighting as MRSE, TAIR, output measures of TM-30-15, CCT and spectrum of activity for melantopic light effects ("melaopic lux level"), percent flicker $\left(F_{\%}\right)$ and flicker index $\left(F_{i}\right)$ in the quality standards, handbooks and procurement procedures for the 
projects, over time in building standards, norms and regulations. By the applying right lighting parameters contributes to human's health and quality of life.

Study show that existing lighting standards and norms are not aware of actual physical and emotional effect of lighting provided by modern applications. Lighting is an essential part of visual environment planning. Lighting settings and quality parameters should be taken into consideration and assessed during the evaluation of visual environment of real estate or urban development projects. The methodology of evaluation needs to be developed in the process of further research.

\section{References}

Cuttle, C. (2015). Lighting design: A perception-based approach. Abingdon: Routledge. $132 \mathrm{p}$.

Cuttle, C. (2017). A fresh approach to interior lighting design: The design objective - direct flux procedure. Lighting Research \& Technology, 50(8), 1142-1163. https://doi.org/10.1177/1477153517734401

Cuttle, C. (2018). The Lighting Design Objectives (LiDOs) Procedure. Retrieved from https://www.ies.org/fires/the-lighting-design-objectives-lidos-procedure/

European Committee for Standardization (CEN). (2011). Light and lighting - Lighting of work places - Part 1: Indoor work places (EN 12464-1). Brussels, Belgium. Retrieved from https://issuu.com/licht.de/docs/guide-din-en-12464-1

Fördergemeinschaft Gutes Licht. (2013). Guide to DIN EN 12464-1.

Fördergemeinschaft Gutes Licht. (2018). Guide to Human Centric Lighting (HCL) for Design and Implementation.

Illuminating Engineering Society (IES). (2011). The lighting handbook $\left(10^{\text {th }} \mathrm{ed}\right.$.). Retrieved from https://www.ies.org/product/thelighting-handbook-10th-edition/

Illuminating Engineering Society (IES). (2018). IES method for evaluating light source color rendition. ANSI/IES TM-30-18.

LightingEurope. (2014). Human centric lighting. A basic overview. Retrieved from https://www.lightingeurope.org/images/publications/general/Human_Centric_Lighting_general_overview_September_2014.pdf

LightingEurope. (2016). Strategic Roadmap 2025 of the European Lighting Industry. Retrieved from https://www.lightingeurope.org/images/160404-LightingEurope_Roadmap---final-version.pdf

Lucas, R. J., Peirson, S. N., Berson, D., Brown, T., Cooper, H., Czeisler, C., Figueiro, M., Gamlin, P., Lockley, S., O’Hagan, J., Price, L., Provencio, I., Skene, D., \& Brainard, G. (2014). Measuring and using light in the melanopsin age. Trends in Neurosciences, 37(1), 1-9. https://doi.org/10.1016/j.tins.2013.10.004

McKinsey \& Company. (2012). Lighting the way: Perspectives on the global lighting market ( $2^{\text {nd }}$ ed.).

Rea, M. S. (Ed.). (2000). The IESNA lighting handbook: Reference and application ( $9^{\text {th }}$ ed.). NY: Illuminating Engineering Society of North America.

The Institute of Electrical and Electronics Engineers (IEEE). (2015). IEEE recommended practices for modulating current in highbrightness LEDs for mitigating health risks to viewers. New York.

U.S. Department of Energy's Office of Energy Efficiency and Renewable Energy. (2015). Evaluating color rendition using IES TM-30-15; PNNL-SA-114005.

Wilkins, A. J., Veitch, J., \& Lehman, B. (2010). LED lighting flicker and potential health concerns: IEEE standard PAR1789 update. In Proc. IEEE Energy Conversion Congress and Exposition (pp. 171-178). Atlanta, GA, USA.

https://doi.org/10.1109/ECCE.2010.5618050 